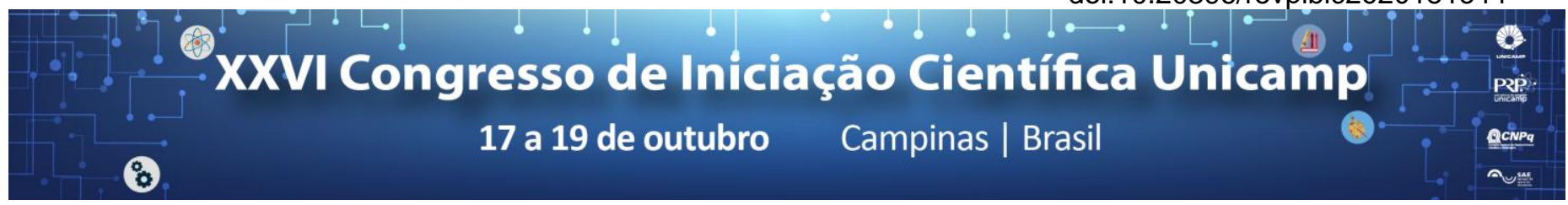

\title{
Operações ótimas para redes de abastecimento de água em estado anômalo.
}

\author{
Victor V. Petrin^, Bruno M. Brentan, Edevar Luvizotto Jr.
}

\section{Resumo}

O abastecimento de água insere-se como infraestrutura fundamental para o desenvolvimento seguro das cidades, tornando a eficiência no controle da operação dos sistemas e a agilidade na detecção e solução dos problemas fatores essenciais para o adequado atendimento da população. Este trabalho visa estimar localização de eventos anômalos previamente detectados a partir da comparação entre séries temporais dos níveis reais dos reservatórios dos diferentes setores previstos por modelo baseado em rede neural artificial. Após a localização do evento, propõe-se o isolamento da região afetada de maneira com que as operações necessárias para o reestabelecimento do serviço de distribuição sejam otimizadas e as consequências do isolamento minimizadas.

\section{Palavras-chave:}

Abastecimento de água, detecção de anomalia, otimização do isolamento.

\section{Introdução}

Alguns eventos comuns na rede de abastecimento, como rupturas, vazamentos, consumo não faturado, problemas mecânicos em válvulas, bombas e sensores, além de ataques terroristas e ataques virtuais podem prejudicar a gestão ótima por parte das empresas de abastecimento, levando a serviços menos eficientes [1]. Nesse sentido, é fundamental que identificação de um evento anômalo e a operação de manobras das válvulas de isolamento seja realizada em tempo hábil a fim de evitar maiores danos [2]. Esse trabalho tem o intuito de, a partir da localização do setor afetado, desenvolver uma rotina para definição de manobras ótimas de isolamento de regiões sob eventos anômalos e acelerar o processo de reestabelecimento do serviço a fim de minimizar a área desabastecida. Os efeitos do fechamento de válvulas serão considerados, de tal modo que, o plano de ações em situações adversas não seja também uma fonte de novos problemas.

\section{Resultados e Discussão}

Para a obtenção dos resultados utilizou-se duas redes fictícias: rede D-town, composta por 5 setores, cujos dados gerados foram utilizados para a criação das redes neurais sem anomalias e a rede Gomes, composta apenas por 2 setores, cujos dados gerados foram utilizados para a criação das redes neurais com anomalias. Para a rede Dtown, a partir de dados temporais, valores de vazão nas bombas e níveis de reservatórios, foi realizado o treinamento e validação para cada reservatório de cada um dos 5 setores da rede.

Tabela 1. Exemplo da taxa de acerto de treinamento, validação e teste para o Reservatório 1 do segundo setor da rede $\mathrm{D}$-town

\begin{tabular}{|l|l|l|l|}
\hline & Treinamento & Validação & Teste \\
\hline Setor 2- Reservatório 1 & 0.9595 & 0.93848 & 0.93268 \\
\hline
\end{tabular}

Para a rede Gomes, foram utilizados para o primeiro setor dados de pressão no nó crítico, nível de reservatório e vazão nas bombas, além dos dados temporais como hora do dia e dia da semana. Para o segundo setor, além dos dados utilizados para o primeiro setor, utilizou-se valores de vazão na válvula de entrada, no lugar dos dados de vazão nas bombas.
Tabela 2. Taxa de acerto de treinamento, validação e teste para cada um dos reservatórios da rede Gomes

\begin{tabular}{|l|l|l|l|}
\hline & Treinamento & Validação & Teste \\
\hline Setor 1 & 0.82486 & 0.62067 & 0.55147 \\
\hline Setor 2 & 0.94446 & 0.89777 & 0.90235 \\
\hline
\end{tabular}

O gráfico a seguir apresenta 0 detalhamento dos resultados das comparações entre níveis previstos pela rede neural e reais do reservatório do setor 2 da rede $D$ town, onde o eixo y representa o nível do reservatório em metros e 0 eixo $x$ representa o tempo em minutos. $O$ traçado azul mostra os dados reais e o vermelho, os previstos.

Figura 1. Comparação entre níveis de reservatório reais e previstos - Reservatório 1, Setor 2 da rede D-town

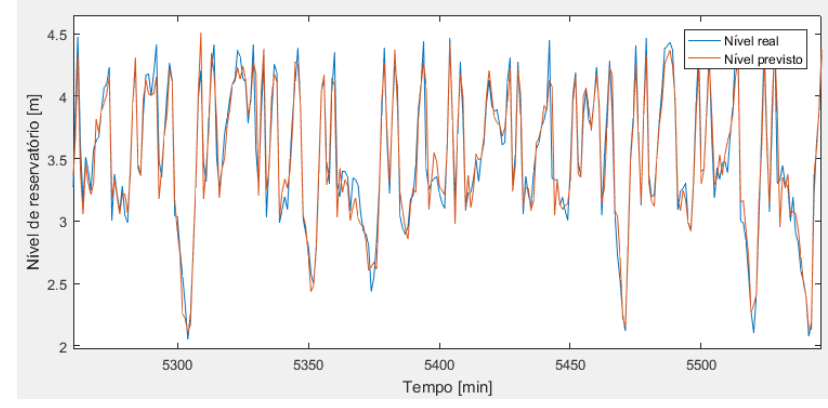

\section{Conclusões}

Analisando os resultados referentes ao treinamento, validação e teste da rede sem anomalias, percebe-se que mostraram-se muito satisfatórios, apresentando uma taxa de acerto superior a $93 \%$ para todos os reservatórios de todos os setores. Para a rede com anomalias percebemos uma sensível diminuição da taxa de acerto mas ainda assim uma grande aproximação dos valores reais e previstos pela rede neural, o que possibilita a indentificação da localização do setor afetado pelo evento anômalo.

${ }^{1}$ Cárdenas, Alvaro A., et al. "Attacks against process control systems: risk assessment, detection, and response." Proceedings of the 6th ACM symposium on information, computer and communications security. ACM, 2011.

${ }^{2}$ Pérez, Ramon, et al. "Methodology for leakage isolation using pressure sensitivity analysis in water distribution networks." Control Engineering Practice 19.10 (2011): 1157-1167. 